\title{
Aquathermolysis of conventional heavy oil with superheated steam
}

\author{
Song Guangshou ${ }^{1}$ Zhou Tiyao ${ }^{2 *}$, Cheng Linsong ${ }^{2}$, Wang Yunxian ${ }^{3}$, \\ Tian Guoqing ${ }^{2,4}$, Pi Jian $^{2,5}$ and Zhang Zheng ${ }^{2}$
}

\author{
${ }^{1}$ Department of Geology, Northwest University, Xi'an, Shaanxi 710069, China \\ ${ }^{2}$ Key Laboratory of Petroleum Engineering, Ministry of Education, China University of Petroleum, Beijing 102249, China \\ ${ }^{3}$ China National Offshore Oil Co. Ltd-Tianjin, Tianjin 300452, China \\ ${ }^{4}$ NO.6 Oil Production Plant, PetroChina Changqing Oilfield Company, Xi'an, Shaanxi 710018, China \\ ${ }^{5}$ Research Center, China National Offshore Oil Corporation, Beijing 100027, China
}

\begin{abstract}
This paper presents a new aquathermolysis study of conventional heavy oil in superheated steam. A new high temperature autoclave was designed, where volume and pressure could be adjusted. Aquathermolysis was studied on two different conventional heavy oil samples under different reaction times and temperatures. Experimental results show that aquathermolysis does take place for conventional heavy oil. As reaction time increases, the oil viscosity reduces. However, the reaction will reach equilibrium after a certain period of time and won't be sensitive to any further reaction time any more. Analysis shows that, while resin and asphaltenes decrease, saturated hydrocarbons and the $\mathrm{H} / \mathrm{C}$ ratio increase after reaction. The main mechanism of aquathermolysis includes hydrogenization, desulfuration reaction of resin and asphaltenes, etc.
\end{abstract}

Key words: Conventional heavy oil, superheated steam, aquathermolysis, viscosity reduction

\section{Introduction}

Clark et al (1983) studied the high-temperature hydrolysis and thermolysis of tetrahydrothiophene and found that the hydrolysis of tetrahydrothiophene produced hydrogen sulphide, carbon dioxide and hydrocarbon gas, together with a complex array of liquid products. A few years later, by means of analyzing compositions and gases of heavy oils from Canada (Clark et al, 1984a; 1984b; 1984c; 1987a; $1987 b ; 1990 a ; 1990 b)$, researchers found that, under hightemperature and high-pressure conditions, desulfuration, denitrification, hydrogenization and water-gas-shift reactions could occur between heavy oil and steam. They referred to this process as aquathermolysis.

The effect on Cold Lake crude oil during steam stimulation was studied (Gould, 1983). After steam stimulation, H/C ratio decreased and aromatic carbon increased. The study concluded that some changes had occurred during aquathermolysis of heavy oil, which included side-chain dealkylation, aromatization of hydroaromatic rings and alteration of some heteroatomic functional groups, etc.

In recent years, more and more attention has been given to aquathermolysis of heavy oil. Fan and Liu found that the viscosity of heavy oil from the Liaohe Oilfield, Northeast China, decreased significantly after aquathermolysis. The contents of heteroatoms, such as $\mathrm{S}, \mathrm{O}$, and $\mathrm{N}$, reduced

* Corresponding author. email: tianyou1019@163.com

Received April 17, 2008
(Fan et al, 2001a; 2001b; 2002; Zhao et al, 2002). Further experimental study indicated that the reaction could be promoted by adding catalysts (Liu et al, 2004; Fan et al, 2004; 2007). This technology has been successfully applied in the field with good results. For super-heavy oil from the Shengli Oilfield, China, the viscosity could reduce by more than $70 \%$ after catalytic aquathermolysis in the presence of a hydrogen donor (Fan et al, 2006).

Most studies tend to focus on the composition analyses of gas and liquid products when analyzing mechanisms of aquathermolysis. Heavy oils used by Clark et al (1987b) contained high percentage of sulfur, and samples from Liaohe Oilfields (Fan et al, 2001b) were ultra heavy oils. They paid more attention to improving the catalysts. However, the importance of system pressure on the reaction has not been investigated. Furthermore, the previous studies of aquathermolysis were only focused on super-heavy oil. The reaction of conventional heavy oil has not been studied.

To study the two issues mentioned above, we designed a new high-temperature autoclave, where pressure could be controlled. Based on the autoclave design principle published (Du et al, 2001; 2002), we made a volume-variable autoclave. In this autoclave, aquathermolysis of conventional heavy oil with superheated steam was studied.

\section{Experimental}

\subsection{Experimental materials}

Distilled water and two crude oil samples, whose properties are listed in Table 1, were used in the experiments. 
Table 1 Ultimate analysis and properties of crude oil samples

\begin{tabular}{cccccccccc}
\hline Oil sample & Oilfield & $\begin{array}{c}\text { Relative } \\
\text { density }\end{array}$ & $\begin{array}{c}\text { Viscosity, mPa.s } \\
/ \text { temperature, }{ }^{\circ} \mathrm{C}\end{array}$ & $\mathrm{C}, \%$ & $\mathrm{H}, \%$ & $\mathrm{O}, \%$ & $\mathrm{~N}, \%$ & $\mathrm{~S}, \%$ & $\mathrm{H} / \mathrm{C}$ \\
\hline 1 & Kenneyak Oilfield & 0.91 & $82.97 / 40$ & 86.41 & 12.33 & 0.21 & 0.15 & 0.900 & 1.71 \\
2 & Bozhong 25-1 oil field & 0.87 & $3760 / 50$ & 81.45 & 11.3 & - & - & 0.326 & 1.66 \\
\hline
\end{tabular}

\subsection{Experimental apparatus}

Aquathermolysis of conventional heavy oil was conducted in a high-temperature autoclave we made. Fig. 1 shows the schematic section of the autoclave. The body and the lid of the autoclave were made of stainless steel for better corrosion resistance. The internal pressure was controlled by manually adjusting the autoclave volume, ensuring that water in the autoclave was superheated. The maximum operating temperature and pressure were $350^{\circ} \mathrm{C}$ and $40 \mathrm{MPa}$, respectively. The volume of this autoclave ranged from 50 to $300 \mathrm{ml}$.

The viscosity of oil samples was measured with a NDJ-1 rotary viscosimeter (provided by Shanghai Ande Instrument Equipment Co., Ltd.). A water thermostat system was used to keep the samples at a specified temperature when their viscosity was measured.

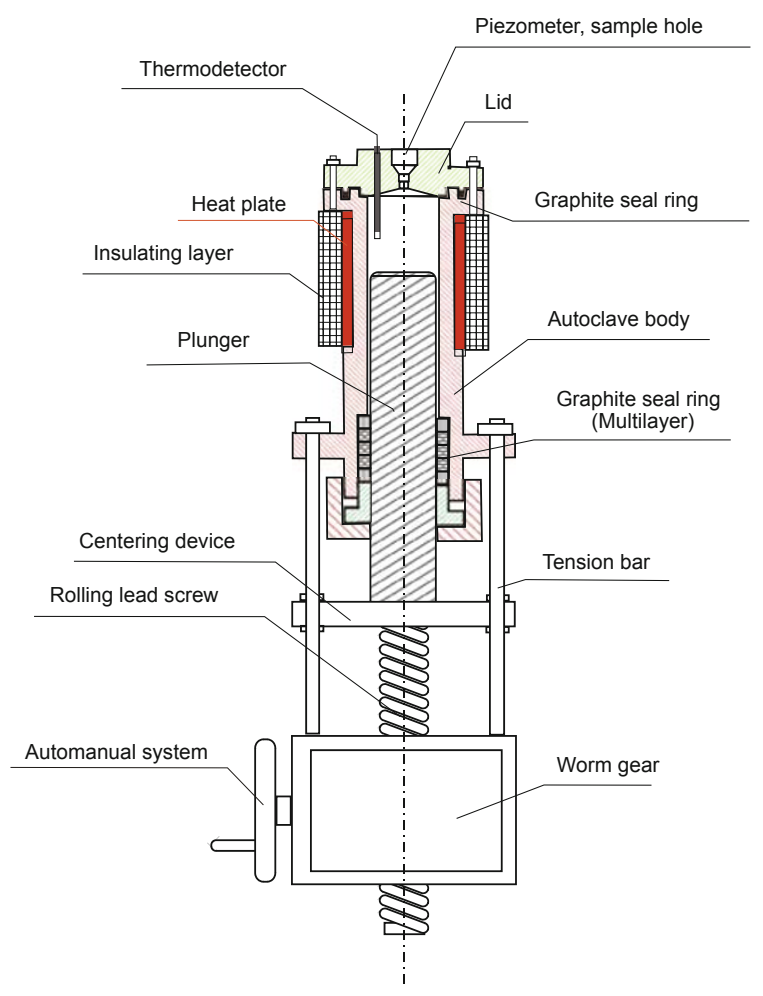

Fig. 1 Schematic section of the high-temperature autoclave

The composition of oil samples were analyzed by China State Key Laboratory of Heavy Oil Processing, China University of Petroleum. The hydrocarbon distribution was analyzed by gas chromatography with the ASTM D5307 standard procedure (Agilent 6890). Elemental composition of the samples was determined with a Carlo Erba EA1108 model elemental analyzer using 3-4 mg samples.
Saturates, aromatics, resins, and asphaltenes (SARA) analysis of oil samples were determined by high performance liquid chromatographic analysis of the deasphalted oil ( $\mathrm{SH} /$ T0509-92). The asphaltene was removed by precipitation with addition of 40-volume excess of dry hexane to the solution of the heavy oil sample in dichloromethane.

\subsection{Experimental procedure}

Based on previous studies, the influence of other factors was neglected and the mass ratio of water to oil was kept at 0.3 during the entire experiment, and the influence of reaction time and temperature on aquathermolysis of conventional heavy oil was investigated. First, keep the autoclave at the minimum volume and fill it with $50 \mathrm{~g}$ crude oil and $15 \mathrm{~g}$ distilled water. Maintain the reaction temperature at 240, 300, and $350{ }^{\circ} \mathrm{C}$, respectively. Set reaction time as $24,36,48$ and $72 \mathrm{~h}$. When heated to the set-point, the pressure of system will increase. This can be controlled by manually adjusting the autoclave volume, ensuring that water in the autoclave is superheated. After reaction, put the oil into the water thermostat system. Finally measure the oil viscosity using the viscosimeter.

\section{Results and discussion}

Table 2 shows the experimental pressures at different experimental temperatures. This indicates that all the reactions has occurred in the superheated steam system at high temperatures.

Table 2 Comparison of experimental pressures and steam saturation pressures

\begin{tabular}{cccc}
\hline $\begin{array}{c}\text { Crude oil } \\
\text { sample }\end{array}$ & $\begin{array}{c}\text { Experimental } \\
\text { pressure } \\
\mathrm{MPa}\end{array}$ & $\begin{array}{c}\text { Experimental } \\
\text { temperature } \\
{ }^{\circ} \mathrm{C}\end{array}$ & $\begin{array}{c}\text { Degree of } \\
\text { superheat } \\
{ }^{\circ} \mathrm{C}\end{array}$ \\
\hline 1 & 0.50 & 240 & 88 \\
& 1.60 & 300 & 99 \\
2 & 4.10 & 350 & 98 \\
\hline
\end{tabular}

\subsection{Hydrocarbon distribution}

Fig. 2 show the distribution of hydrocarbons in oil samples before and after aquathermolysis. The corresponding reaction temperatures were 300 and $350{ }^{\circ} \mathrm{C}$, respectively. The components of crude oil changed noticeably, and the content of high carbon number hydrocarbons became lower and the 
content of light hydrocarbons higher.

Analysis results proved that conventional heavy oil could react with superheated steam at high temperatures and the crude oil was upgraded. The decrease in high carbon number hydrocarbons indicates that the main reason is the cracking of long-chain hydrocarbons.

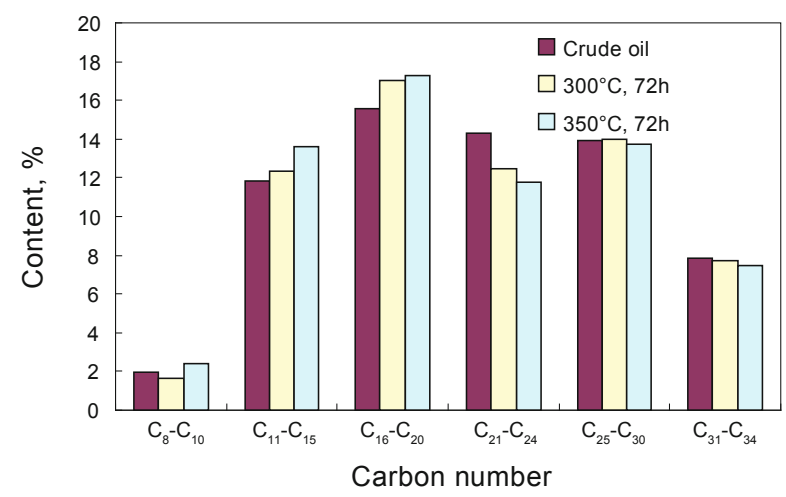

Fig. 2 Hydrocarbon distribution of $1^{\#}$ oil sample before and after aquathermolysis

\subsection{SARA analysis and element analysis}

SARA analysis and element analysis of oil samples were carried out before and after reaction and experimental results are shown in Table 3.

A significant increase in the content of saturates was observed for $1^{\#}$ oil sample after aquathermolysis at $350{ }^{\circ} \mathrm{C}$ for $72 \mathrm{~h}$ and for $2^{\#}$ oil sample after aquathermolysis at $300{ }^{\circ} \mathrm{C}$ for $36 \mathrm{~h}$. However, a decrease in the contents of resin and asphaltenes were also observed due to the thermolysis of condensed nucleus and heterocyclic compounds. An increase in $\mathrm{H} / \mathrm{C}$ ratio after reaction indicated that hydrogenization took place in the thermolysis process.

For $1^{\#}$ oil sample, the aromatics content increased first and then decreased as reaction temperature increased. For $2^{\#}$ oil sample, the aromatics content decreased noticeably. The phenomena can be explained by hydrogenization and side-chain dealkylation of hydroaromatic rings.

In crude oil, sulfur exists as thioalcohols, sulfur ethers, and thiophenes. The sulfur content reduced after reaction, which illustrated that the carbon-sulfur bond might be broken and gaseous sulfides might escape.

Table 3 SARA components and elementary composition of crude oil samples before and after aquathermolysis

\begin{tabular}{|c|c|c|c|c|c|c|c|c|}
\hline \multirow{2}{*}{$\begin{array}{c}\text { Crude oil } \\
\text { sample }\end{array}$} & \multirow{2}{*}{$\begin{array}{c}\text { Reaction } \\
\text { temperature, }{ }^{\circ} \mathrm{C}\end{array}$} & \multirow{2}{*}{$\begin{array}{c}\text { Reaction } \\
\text { time, } \mathrm{h}\end{array}$} & \multicolumn{4}{|c|}{ SARA, wt $\%$} & \multirow{2}{*}{$\mathrm{H} / \mathrm{C}$} & \multirow{2}{*}{ S } \\
\hline & & & Saturates & Aromatics & Resins & Asphaltenes & & \\
\hline \multirow{3}{*}{1} & Before reaction & & 63.37 & 25.00 & 10.98 & 0.65 & 1.71 & 0.90 \\
\hline & 300 & 72 & 63.61 & 25.10 & 10.64 & 0.65 & 1.72 & 0.89 \\
\hline & 350 & 72 & 66.18 & 24.98 & 8.39 & 0.45 & 1.72 & 0.86 \\
\hline \multirow{2}{*}{2} & Before reaction & & 45.81 & 26.81 & 24.81 & 2.57 & 1.59 & 0.326 \\
\hline & 300 & 36 & 52.88 & 22.62 & 22.62 & 1.88 & 1.65 & 0.315 \\
\hline
\end{tabular}

\subsection{Effects of reaction time}

Aquathermolysis of heavy oil samples was conducted at $240{ }^{\circ} \mathrm{C}$ for different periods of reaction time $(24,36,48$ and $72 \mathrm{~h}$ ). Figs. 3 and 4 show the effect of reaction time on viscosity of oil samples. After reaction, the viscosity of oil samples reduced significantly. The viscosity of oil samples decreased with reaction time before $48 \mathrm{~h}$, and after the reaction time exceeded $48 \mathrm{~h}$, the oil viscosity reduction became very slight. The result indicated that the reaction would reach its equilibrium after $48 \mathrm{~h}$.

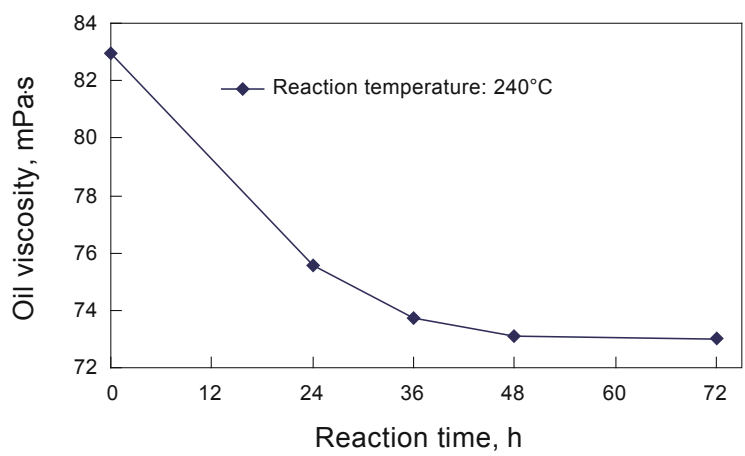

Fig. 3 Effect of reaction time on the viscosity of $1^{\#}$ oil sample

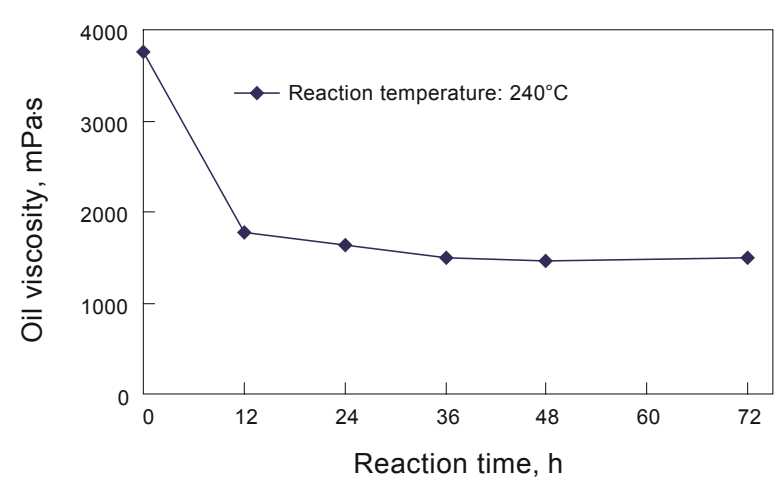

Fig. 4 Effect of reaction time on the viscosity of $2^{\#}$ oil sample

\subsection{Effects of reaction temperature}

In order to study the effect of reaction temperature on the aquathermolysis of heavy oil sample, experiments were conducted on $1^{\#}$ oil sample at different temperatures $(240$, 300 , and $350{ }^{\circ} \mathrm{C}$ ). The reaction time was kept constant at $72 \mathrm{~h}$ to eliminate its influence.

Fig. 5 shows the viscosity of oil samples after reaction. Even as the reaction temperature was raised from 240 to 300 
${ }^{\circ} \mathrm{C}$, the viscosity changed very slightly. However, when the reaction temperature was raised to $350{ }^{\circ} \mathrm{C}$, the viscosity of oil sample declined sharply. Previous research has demonstrated that the optimum temperature range of aquathermolysis of heavy oil is $220-280{ }^{\circ} \mathrm{C}$ (Liu et al, 2004). Based on the previous research and experimental results obtained in this study, the viscosity of $1^{\#}$ oil sample is not very sensitive to reaction temperature during a $72 \mathrm{hr}$ reaction time, but it reduces quickly at a higher temperature. This may be due to thermolysis of crude oil at high temperatures.

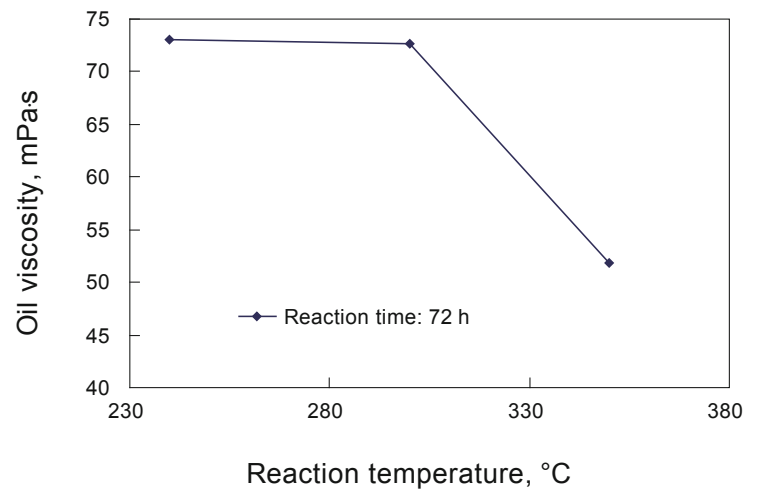

Fig. 5 Effect of reaction temperature on the viscosity of $1^{\#}$ oil sample

\subsection{Reversion of decreased towards original value on ageing}

The reduction in viscosity after aquathermolysis is not fully sustained. The viscosity of reacted oil $1^{\#}$ gradually increased back towards its original higher viscosity, as shown in Fig. 6. The oil which had been subject to aquathermolysis for a longer time ( $72 \mathrm{~h}$ vs. $24 \mathrm{~h}$ ) retained more of its viscosity reduction $(7.1 \%)$ on ageing for about two weeks than did the oil reacted for only 24 hours (3.5\% reduction).

During aquathermolysis, a number of active chains may be produced due to side-chain dealkylation and alteration of some heteroatomic functional groups (Zhao et al, 2002). Theses active chains can polymerize to form large molecular compounds, thus leading to the increase in viscosity with time.

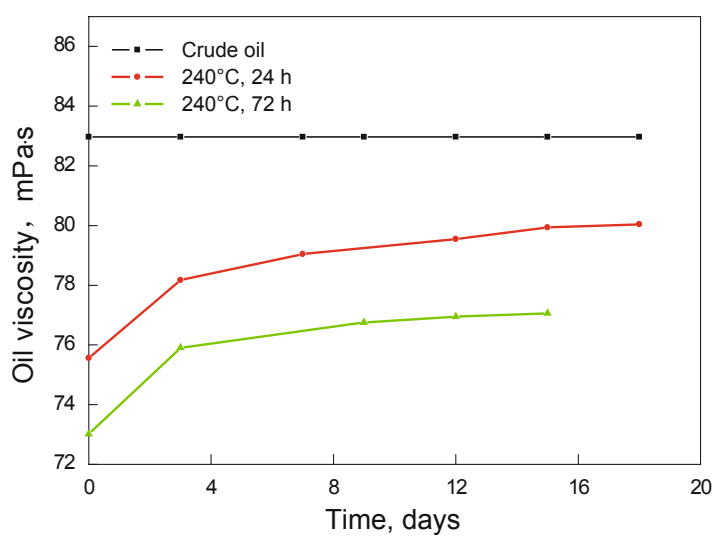

Fig. 6 Stability analysis of viscosity reduction

\section{Conclusions}

1) The reactions between conventional heavy oil and superheated steam were investigated for the first time. Experimental results demonstrated that aquathermolysis did take place. The content of high carbon number hydrocarbons decreased and light hydrocarbons increased. The viscosity of conventional crude oil reduced and the oil was upgraded after aquathermolysis.

2) After 48 hours, the aquathermolysis reached a state of chemical equilibrium for conventional crude oil. After reaction equilibrium, aquathermolysis was not sensitive to reaction time.

3) The main mechanisms of aquathermolysis between conventional heavy oil and superheated steam included hydrogenization, desulfuration reaction of resin and asphaltenes, etc.

\section{Acknowledgements}

Reviews and helpful comments from Xian-Huan Wen and William Shu of Chevron International Exploration and Production Company are greatly appreciated. The financial support from the National Natural Science Foundation of China (Grant No.50276040) is gratefully acknowledged.

\section{References}

Clark P D, Clarke R A and Hyne J B. Studies on the chemical reactions of heavy oils under steam stimulation conditions. AOSTRA Journal of Research. 1990a. 6: 29-39

Clark P D, Clarke R A and Hyne J B. Studies on the effect of metal species on oil sands undergoing steam treatments. AOSTRA Journal of Research. 1990b. 6: 53-64

Clark P D, Dowling N I and Hyne J B. The chemistry of organosulphur compound types occurring in heavy oils. 4. The high-temperature reaction of thiophene and tetrahydrothiophene with aqueous solutions of aluminium and first-row transition-metal cations. Fuel. 1987a. 66: 1353-1357

Clark P D, Dowling N I, Lesage K L, et al. Chemistry of organosulphur compound types occurring in heavy oil sands. 5. Reaction of thiophene and tetrahydrothiophene with aqueous Group VIIIB metal species at high temperature. Fuel. 1987b. 66: 1699-1702

Clark P D and Hyne J B. Chemistry of organosulphur compound types occurring in heavy oil sands. 3. Reaction of thiophene and tetrahydrothiophene with vanadyl and nickel salts. Fuel. 1984a. 63: 1649-1654

Clark P D and Hyne J B. Steam-oil chemical reactions: mechanisms for the aquathermolysis of heavy oil. AOSTRA Journal of Research. 1984b. 1: 15-20

Clark P D, Hyne J B and Tyrer J D. Chemistry of organosulphur compound types occurring in heavy oil sands. 1. High temperature hydrolysis and thermolysis of tetrahydrothiophene in relation to steam stimulation processes. Fuel. 1983. 62: 959-962

Clark P D, Hyne J B and Tyrer J D. Some chemistry of organosulphur compound types occurring in heavy oil sands. 2. Influence of $\mathrm{pH}$ on the high temperature hydrolysis of tetrahydrothiophene and thiophene. Fuel. 1984c. 63: 125-128

Du H W, Fang W, Huo Q, et al. Development of high temperature and high pressure thermal modeling unit. Petroleum Instruments. 2001. 15(6): 16-19 (in Chinese)

Du H W and Sun Y H. Development of non-bolt, quick-released caldron with high temperature and high pressure. Petroleum Instruments. 
2002. 16(5): 15-16 (in Chinese)

Fan H F, Li Z B and Liang T. Experimental study on using ionic liquids to upgrade heavy oil. Journal of Fuel Chemistry and Technology. 2007. 35(1): 32-35

Fan H F, Liu Y J, Zhang L Y, et al. The study on composition changes of heavy oils during steam stimulation processes. Fuel. 2002. 81: 17331738

Fan H F, Liu Y J and Zhao X F. Study on composition changes of heavy oils under steam treatment. Journal of Fuel Chemistry and Technology. 2001a. 29(3): 269-272 (in Chinese)

Fan H F, Liu Y J, Zhao X F, et al. Studies on effect of metal ions on the aquathermolysis reaction of Liaohe heavy oils under steam treatment. Journal of Fuel Chemistry and Technology. 2001b. 29(5): 430-432 (in Chinese)

Fan H F, Zhang Y and Lin Y J. The catalytic effects of minerals on aquathermolysis of heavy oils. Fuel. 2004. 83: 2035-2039

Fan Z X, Zhao F L, Wang J X, et al. Upgrading and viscosity reduction of super heavy oil by aqua-thermolysis with a hydrogen donor. Journal of Fuel Chemistry and Technology. 2006. 34(3): 315-318 (in Chinese)

Gould K A. Influence of thermal processing on the properties of Cold Lake asphaltenes. 2. Effect of steam treatment during oil recovery. Fuel. 1983. 62(2): 370-372

Liu Y J, Zhong L G, Jiang S J, et al. Research progress of recovering heavy oil by aquathermolysis. Journal of Fuel Chemistry and Technology. 2004. 32(1): 117-122 (in Chinese)

Zhao X F, Liu Y J, Fan H F, et al. Study on feasibility of heavy oil aquathermolysis. Journal of Fuel Chemistry and Technology. 2002. 30(4): 381-384 (in Chinese)

(Edited by Sun Yanhua) 